\title{
Peran Media Sosial Instagram \\ Dalam Upaya Menjaga Eksistensi Bahasa Bali
}

\author{
Gusti Nyoman Mastini ${ }^{1}$, Ni Ketut Kantriani ${ }^{2}$, Ni Wayan Arini ${ }^{3}$ \\ ${ }^{123}$ Universitas Hindu Negeri I Gusti Bagus Sugriwa Denpasar \\ ${ }^{1}$ nyomanmastini2@gmail.com, ${ }^{2}$ ketutkantriani@gmail.com, \\ ${ }^{3}$ wayanarini1967@gmail.com,
}

\begin{tabular}{l}
\hline Keywords: \\
\hline Social Media, \\
Instagram, \\
Balinese \\
Language \\
\hline
\end{tabular}

\begin{abstract}
Language is one of the main needs and has a very important role in social life. Balinese as a mother tongue is one of the identities and ancestors that must be maintained and maintained properly. Existence can also be known by one word, namely specific presence. Where the existence in question is the reaction of the individuals around us which show that our reality is perceived. This paper aims to describe the role of social media Instagram in an effort to maintain the existence of the use of the Balinese language. The method used in this study is a qualitative method with descriptive analysis techniques. The results show that on Instagram social media accounts such as @wikibasabali, @ Bahasa_bali which contains a bold three-language dictionary (Bali-Indonesian-English), virtual libraries, the use of anggah ungguhing basa, the use of Balinese in daily life, as well as on the@beluluk accountwhich presents humor or entertainment in the form of Balinese comics, in this case Instagram is a social media that can be one of the media that plays a role in efforts to maintain the existence of the Balinese language.
\end{abstract}

Kata Kunci:

Media Sosial, Instagram, Bahasa Bali

\begin{abstract}
Abstrak
Bahasa adalah salah satu kebutuhan utama dan memiliki peran yang sangat penting dalam kehidupan bermasyarakat. Bahasa Bali sebagai bahasa ibu merupakan salah satu identitas dan warisan leluhur yang harus dijaga dan dipertahankan dengan baik keberadaannya. Eksistensi juga dapat dikenal dengansatu kata, yaitu kehadiran yang spesifik. Dimana keberadaan yang dimaksud adalah reaksi dari individu-individu di sekitar kita yang menunjukkan bahwa realitas kita dipersepsikan. Tulisan ini bertujuan untuk mendeskripsikan peran media sosial instagram dalam upaya menjaga eksistensi pemakaian bahasa Bali. Penggunaan metode pada penelitian ini adalah metode kualitiatif dengan teknik analisis deskriptif. Hasil penelitian menunjukkan bahwa pada akun-akun media sosial instagram seperti
\end{abstract}


@wikibasabali, @bahasa_bali yang berisikan kamus daring tiga bahasa (Bali-Indonesia-Inggris), perpustakaan virtual, penggunaan anggah ungguhing basa, penggunaan bahasa Bali dalam kehidupan sehari-hari, begitu pula pada akun @beluluk yang menyajikan humor atau hiburan berupa komik berbahasa Bali, dalam hal ini instagram merupakan media sosial yang dapat menjadi salah satu media yang berperan dalam upaya menjaga eksistensi bahasa Bali..

\section{Pendahuluan}

Bahasa adalah salah satu kebutuhan utama dan memiliki peran yang sangat penting dalam kehidupan bermasyarakat. Oleh karena itu, keberadaan bahasa sebagai sarana komunikasi ataupun sebagai media untuk mengutarakan sesuatu yang berkaitan dengan pengembangan wawasan masyarakat penutur bahasa tidak dapat dipisahkan. Bahasa merupakan sistem lambang bunyi yang bersifat arbitrer, yang digunakan oleh masyarakat untuk bekerja sama dan berinteraksi (Kridalaksana, 2001: 21). Bahasa adalah media yang digunakan untuk menyampaikan informasi dari seseorang kepada orang lain dalam bentuk lisan dan tulisan. Seperti halnya yang disampaikan oleh Masinambouw (2012) sistem bahasa memiliki fungsi sarana interaksi sosial manusia, sehingga perilaku berbahasa harus disertai dengan norma-norma yang berlaku. Oleh karena sarana atau alat yang digunakan untuk menyebarkan ilmu pengetahuan, budaya dan teknologi yaitu bahasa, maka perkembangan ilmu pengetahuan, budaya dan teknologi menyebar dengan cepat. Salah satu kearifan local yang dapat mencirikan suatu daerah adalah bahasa.

Bali merupakan pulau yang memiliki berbagai macam warisan leluhur yang masih melekat dalam kehidupan masyarakatnya. Salah satunya adalah bahasa daerah, bahasa Bali sebagai bahasa ibu merupakan salah satu identitas dan warisan leluhur yang harus dipertahankan, dipelihara dengan baik keberadaannya (Suastra, 2009). Dalam bahasa Bali terdapat,tingkatan bahasa atau yang disebut dengan anggah-ungguhing basa. Adanya tingkatan bahasa atau yang disebut dengan anggah-ungguhing basa ini membuat anggapan bahwa bahasa Bali sulit untuk digunakan dalam berkomunikasi. Di kalangan generasi muda pemakaian bahasa daerah di era seperti saat ini sudah mulai diabaikan, penggunaan bahasa daerah dalam pergaulannya dianggap ketinggalan zaman. Hal ini juga menjadi salah satu permasalahan generasi muda saat ini, sehingga kurangnya minat dalam belajar bahasa daerah (Djaharuddin, 2017). 
Kencangnya arus globalisasi serta pesatnya kemajuan Ilmu Pengetahuan dan Teknologi (IPTEK), membuat bahasa Bali kini mulai mengalami pergeseran serta melemahnya penggunaan bahasa Bali terutama dikalangan generasi muda. Penggunaan Bahasa Bali dikalangan generasi muda kini telah digantikan dengan bahasa asing atau bahasa gaul (prokem). Pengaruh bahasa gaul terhadap penggunaan tata bahasa daerah semakin nyata. Masyarakat, khususnya penggunaan bahasa gaul oleh remaja, telah membawa dampak negatif bagi perkembangan bahasa Bali sebagai warisan budaya. Bahasa gaul merupakan bahasa yang berkembang, dan menyebabkan banyak kata-kata menjadi kuno atau usang karena waktu. Meningkatnya penggunaan bahasa gaul di kalangan remaja membuat perbendaharaan kata bahasa gaul semakin banyak, dan komposisinya menjadi tidak stabil (Djaharuddin, 2017). Dalam teori generasi, saat ini generasi muda merupakan generasi alfa. Generasi ini memiliki kecenderungan untuk memaka media sosial sebagai alat belajar dan menyerap segala informasi (Salsabila, 2018).

Teknologi yang semakin canggih membuat masyarakat dengan mudah mengakses informasi secara instan. Mudahnya mengakses internet tak sedikit masyarakat kini menggunakan internet untuk membantu dan mempermudah kegiatannya dalam berbagai aspek kebutuhanya, baik itu sebagai sumber belajar, mencari informasi dan lain sebagainya (Juwita, 2014). Seperti yang telah kita ketahui, masyarakat pada umumnya sudah tidak asing lagi dengan media sosial. Media sosial merupakan media yang digunakan untuk berinteraksi antara individu satu dengan lainnya. Jika ditinjau melalui segi kebahasaan yang digunakan, bahasa dalam media social tidak mengikuti aturan kebakuan, ada kecenderungan pada hal-hal negatif. Namun tidak semua bahasa yang digunakan dalam media social merupakan pemberitaan negatif (Zainal, 2017). Media sosial adalah alat komunikasi untuk memperluas wawasan, hubungan dan pertemanan di seluruh dunia, terhubung melalui Internet. Jejaring sosial termasuk Facebook, Instagram, WhatsApp, Twitter, Tiktok dan Path. Sebagai media informasi dan komunikasi, media sosial juga berperan penting dalam memberikan saran tentang gaya bahasa terkini. Remaja yang masih labil dapat dengan mudah meniru dan meniru bahasa yang ditampilkan di media (Djaharuddin, 2017).

Melihat hal tersebut, ternyata pembelajaran bahasa juga dapat dicapai melalui media sosial. Hal ini dapat dijadikan sebagai salah satu bentuk strategi untuk tetap hidup dalam keterpurukan bahasa Bali. Media sosial memiliki banyak jenis dan bentuk, namun 
pada kesempatan ini, akan lebih terfokus pada media sosial yaitu instagram. Instagram merupakan salah satu media sosial yang disukai oleh masyarakat, tidak hanya remaja, tetapi juga orang dewasa. Tak sedikit remaja menggunakan Instagram untuk kepentingan pribadi, dan lain sebagainya. Dikutip dari databoks.katadata.co.id jumlah pengguna Instagram hingga Juli 2021 di Indonesia mencapai 91,77 juta pengguna. Sedangkan jumlah pengguna aktif Instagram di seluruh dunia mencapai 1,07 miliar. Popularitas Instagram tidak dapat dipisahkan dari fungsinya, yaitu menggunakan foto sebagai alat komunikasi, memungkinkan pengguna untuk membuat galeri pribadi. Instagram juga menyediakan fitur untuk mengedit foto untuk foto-foto yang ditampilkan lebih baik. Tidak hanya itu, Instagram juga memungkinkan pengguna untuk branding diri melalui foto dan subtitle yang dimuat dan tagar (hashtage) yang dapat ditambahkan untuk mengoptimalkan penggunaan SEO (Search Engine Optimizer) (Salsabila,2018). Oleh karena itu dapat dikatakan bahwa remaja dapat menggunakan media sosial Instagram untuk menambah informasi yang dapat memperluas pengetahuannya, dalam hal ini pembelajaran, pelestarian, dan upaya untuk mempertahankan keberadaan bahasa Bali juga tidak hanya dapat dilakukan di sekolah, tetapi juga dapat menggunakan teknologi yang dekat masyarakat saat ini, yaitu Instagram.

\section{Metode}

Metode yang digunakan dalam penelitian ini adalah metode kualitiatif dengan teknik analisis deskriptif. Oleh karena itu, penelitian ini pada dasarnya mencoba untuk mendeskripsikan atau menjelaskan suatu fenomena sosial. Metode ini digunakan untuk memperoleh informasi yang lebih kompleks guna memperoleh informasi yang lebih banyak, yang berguna untuk pengembangan ilmu-ilmu sejenis. Dengan kata lain, tujuan dari metode deskriptif kualitatif ini adalah untuk melakukan kajian yang komprehensif dan mendalam terhadap kondisi atau fenomena yang terjadi dalam kehidupan sehari-hari. (Sarwono, 2006). Pengambilan data dilakukan dengan teknik purposive sampling, data penelitian diambil dari internet, khusus jejaring sosial instagram.

\section{Hasil dan Pembahasan}

Sebagian masyarakat Bali masih menggunakan bahasa Bali untuk berkomunikasi dalam keluarga, tetangga, adat istiadat, agama, pendidikan bahkan media. Beberapa penelitian menunjukkan bahwa 95\% penutur masih memilih menggunakan bahasa Bali 
dalam komunikasi keluarga (Suandi, 2006). Begitu pula penggunaan bahasa Bali dalam lingkungan tetangga masih digunakan, hal terebut merupakan cerminan identitas kebersamaan bagi warga. Demikian juga penggunaan bahasa bali dalam ranah adat yang masih kental digunakan baik itu dalam paum (rapat), serta dalam kegiatan keagamaan lainnya seperti dalam Dharma wacana, Dharma Tula, dan lain sebagainya. Dalam dunia pendidikan, Permendiknas Nomor 22 tahun 2006 tentang standar isi telah memasukkan dan memberikan kesempatan bagi bahasa Bali sebagai mata ajar muatan lokal di tigkat SD, SMP, SMA/SMK dengan alokasi waktu 2 jam pelajaran untuk semua jenjang (Tantra, 2006). Pemerintah Provinsi Bali juga telah melakukan berbagai upaya untuk mendukung pelestarian bahasa Bali, salah satunya dengan menerbitkan Pergub Bali Nomor 80 Tahun 2018 tentang Perlindungan dan Penggunaan Bahasa, Aksara dan Sastra Bali serta Penyelengaraan Bulan Bahasa Bali. Terdapat pada (Pasal 3) Bahasa Bali digunakan sebagai sarana; a). komunikasi dalam kehidupan keluarga Bali; b). komunikasi dalam segala kegiatan agama Hindu, adat, dan budaya Bali; dan c). pemberian informasi pada layanan masyarakat baik pada lembaga pemerintahan maupun lembaga swasta sebagai pendamping Bahasa Indonesia. Pada (Pasal 4) Bahasa Bali digunakan sebagai sarana untuk berkomunikasi oleh pegawai, guru, tenaga kependidikan, peserta didik dan masyarakat di lingkungan lembaga pemerintahan dan lembaga swasta pada hari Kamis, Purnama, Tilem, dan Hari Jadi Provinsi pada tanggal 14 Agustus (Pergub Bali, 2018)

Penggunaan bahasa di bidang media pada saat ini terbilang cukup baik, baik itu di media cetak maupun media online. Perkembangan teknologi saat ini seperti halnya social media, memberi ruang baru bagi sastrawan, penggiat bahasa dalam membagikan edukasi berupa unggahan-unggahan yang berkaitan dengan pelestarian bahasa (Salsabila, 2018). Salah satunya adalah dengan media social instagram. Melaui program ini, banyak karya-karya berbau bahasa Bali yang luar biasa telah diciptakan, yang secara khusus dapat menarik perhatian generasi muda untuk menggunakan bahasa Bali. 

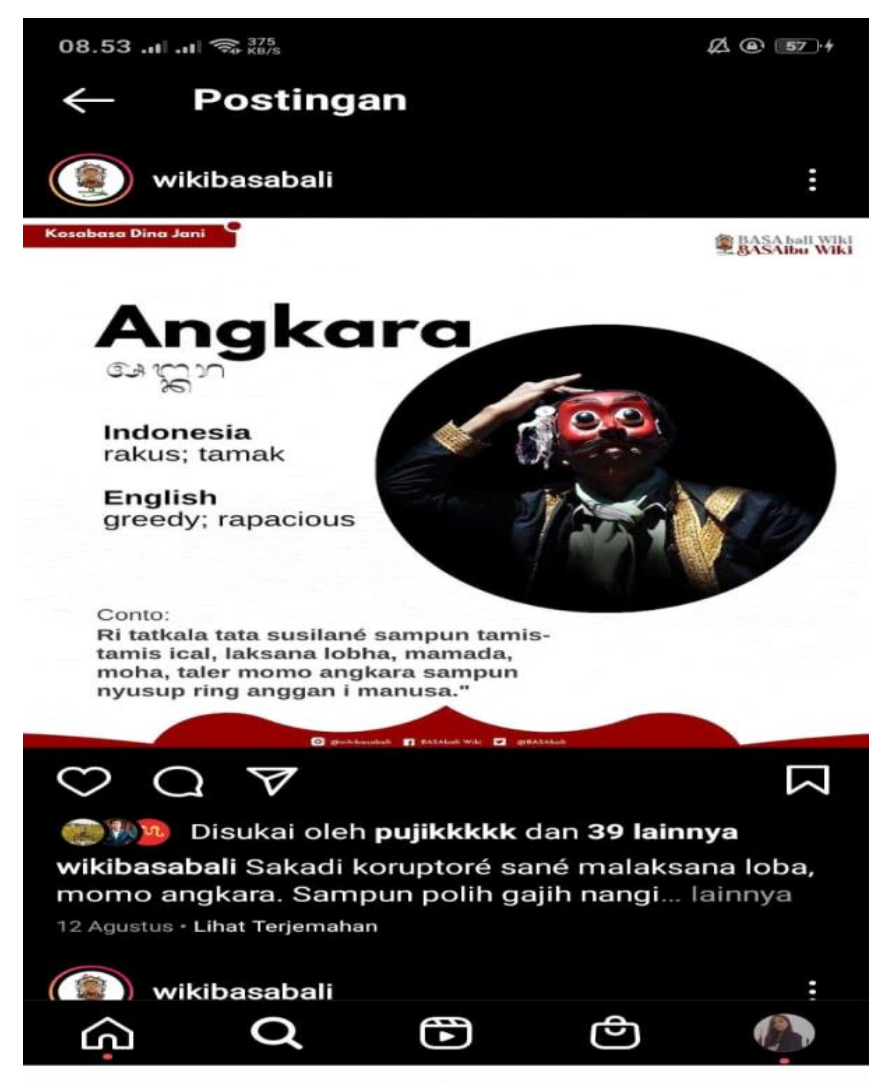

Gambar 1. Screenshot Unggahan Akun @wikibasabali (Kamus daring tiga bahasa)

Berdasarkan hasil penelitian berupa postingan yang mendukung eksistensi bahasa Bali yang dicapture dari postingan yang dilakukan oleh akun@wikibasabali. Akun ini merupakan situs yang berbasis pengetahuan bahasa dan budaya masyarakat Bali. Akun ini memiliki pengikut sebanyak 4.595 dan telah melakukan kiriman sebanyak 1.699 kali. Dengan konten instagram berisi kamus daring tiga bahasa serta perpustakaan virtual. Data pertama pada akun instagram @wikibasabali dari salah satu unggahannya menunjukkan kamus daring tiga bahasa yakni bahasa Bali, bahasa Indonesia, dan bahasa Inggris. Unggahan tersebut memberikan pengetahuan tentang arti kata bahasa Bali dalam bahasa Indonesia dan bahasa Inggris, sekaligus memberikan contoh penggunaannya dalam kalimat berbahasa Bali. Berdasarkan data yang didapatkan diatas, dapat diketahui bahwa akun@wikibasabali yang mendukung penggunaan bahasa Bali di media sosial. Hal ini dibuktikan dengan konten-konten yang diunggah oleh akun tersebut memuat kiriman mengenai penggunaan bahasa Bali yang baik dan benar. Selain itu, tampilan pada akun tersebut juga sangat menarik bagi pembaca. 

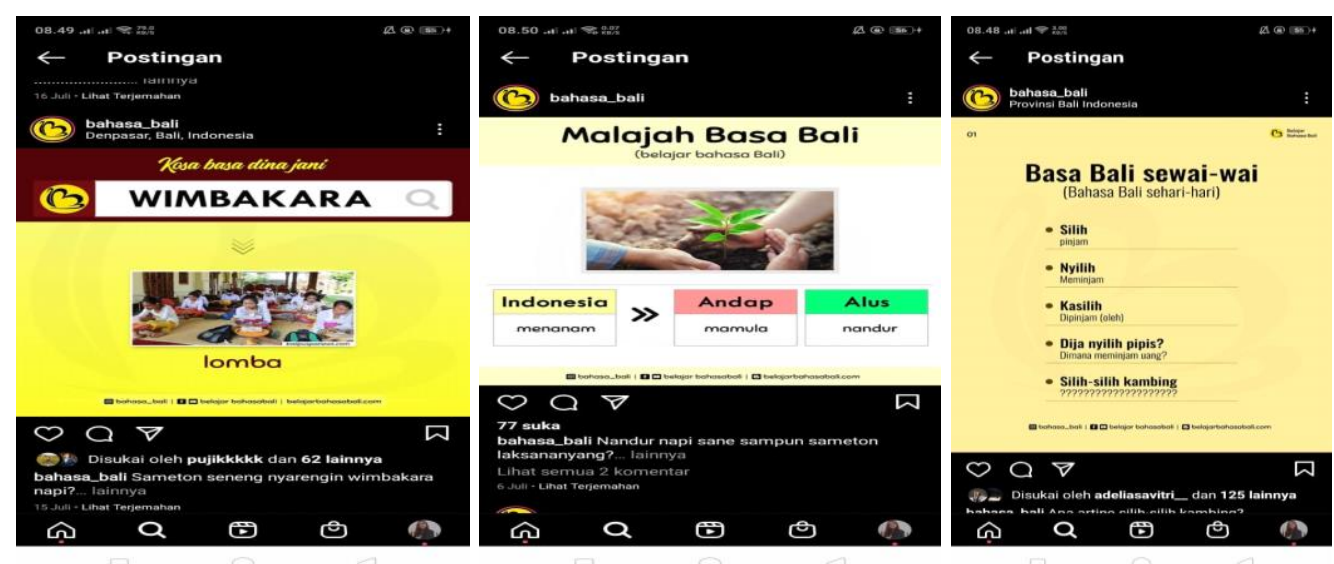

Gambar 2. Screenshot Unggahan Akun @bahasa_bali (Arti kata bahasa Bali, Anggah

Ungguhing Basa, Penggunaan Bahasa Bali di Kehidupan Sehari-Hari)

Tak hanya akun@wikibasabali,namun akun @bahasa_bali juga mengunggah konten yang berperan dalam menjaga dan mengajak para insan muda untuk ikut serta dalam melestarikan bahasa Bali. Di dalam akun tersebut berisikan edukasi mengenai makna kata dalam bahasa Bali, anggah ungguhing basa, penggunaan bahasa Bali dalam kehidupan sehari-hari dan lain sebagainya. Dibandingkan dengan akun @wikibasabali akun ini memiliki pengikut lebih banyak yakni 7.301 pengikut. Dari data yang didapatkan yaitu tiga Screenshot unggahan instagram @bahasa_bali, gambar yang pertama memberikan pengetahuan tentang arti kata bahasa Bali yang terdapat terjemahannya dalam bahasa Indonesia, kemudian pada gambar kedua unggahan akun tersebut memberikan pengetahuan tentang anggah ungguhing basa, seperti contoh dalam unggahan tersebut kata "menanam" dalam bahasa Indonesia, dalam bahasa Bali andap berarti mamula, dalam bahasa Bali alus berarti nandur. Selanjutnya pada gambar ketiga unggahan akun tersebut memberikan pengetahuan tentang bahasa Bali sehari-hari, seperti pada unggahan tersebut dari kata dasar "pinjam" dalam bahasa Indonesia, dalam bahasa Bali berarti silih, kemudian "meminjam" yang artinya nyilih, "dipinjam" yang artinya kasilih dan juga menyertakan pengunaannya dalam sebuah kalimat. Berdasarkan data tersebut dapat menunjukkan bahwa akun instagram @bahasa_bali ikut serta dalam berkontribusi dan memberikan manfaat terhadap eksistensi bahasa Bali dikalangan penguna instagram. 


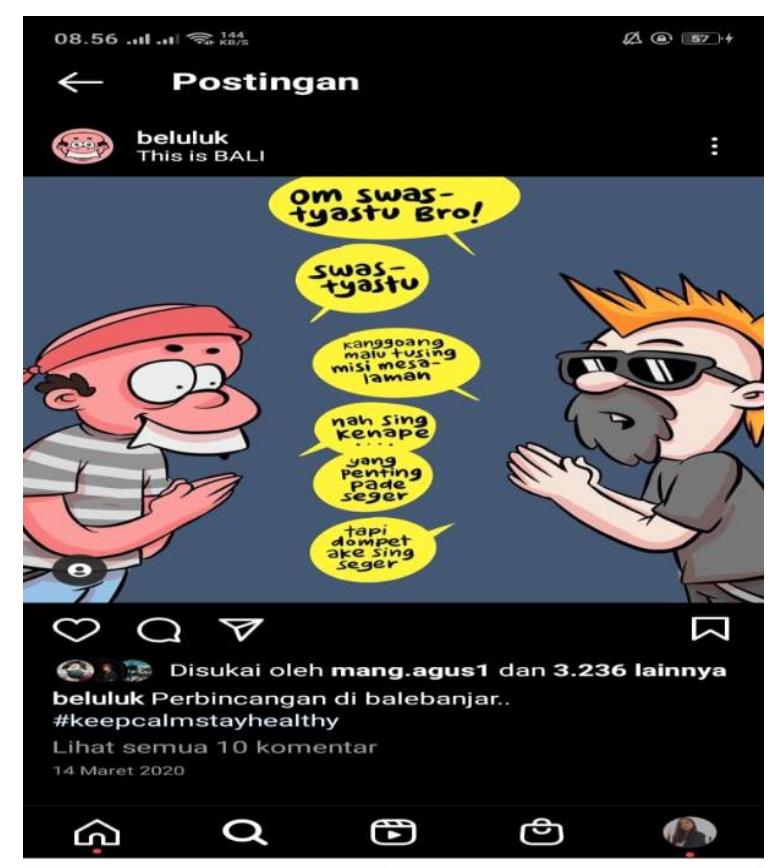

Gambar 3. Screenshot Unggahan Akun @beluluk (Komik bahasa Bali)

Selain sebagai media edukasi dalam menjaga eksistensi bahasa Bali, disisi lain instagram juga mampu menghadirkan hiburan bagi penggunanya, seperti pada akun instagram @beluluk. Akun ini sudah memiliki pengikut yang terbilang banyak yaitu 58,9 ribu dan telah melakukan kiriman sebanyak 1.360 kali, berisikan konten-konten mengedukasi sekaligus menghibur pengikutnya melalui postingan berupa komik bergambar berbahasa Bali. Kerap menghadirkan fenomena-fenomena terkini menggunakan bahasa Bali dengan gambar yang menarik, walaupun bahasa Bali yang digunakan masih terbilang andap (kasar), tetapi disisi lain mengingatkan kita agar tetap menjaga keberadaan bahasa Bali di era sekarang.

Jika dilihat dari satu sisi, instagram memang memiliki dampak yang kurang baik terhadap perkembangan bahasa Bali karena beberapa penggunanya yang menggunakan bahasa asing atau bahasa gaul. Namun, jika dilihat dari sisi lain, instagram harusnya memiliki peranan dalam menjaga eksistensi bahasa dalam hal ini bahasa Bali. Dengan pengguna sebanyak lebih dari 1 milyar, diharapkan konten-konten yang diunggah dalam instagram dapat menjadi sumber belajar bahasa Bali sehingga semua orang bisa kapan saja dan dimana saja dengan mudah belajar bahasa Bali.

Adapun upaya yang dapat dilakukan dalam memanfaatkan instagram sebagai sumber belajar sekaligus menjaga eksistensi bahasa Bali, yakni : 
1. Mengikuti akun-akun edukasi dan mendukung perkembangan bahasa Bali, seperti akun@wikibasabali, @bahasa_bali,dan akun-akun semacamnya.

2. Membagikan hal-hal positif dan edukatif berkenaan dengan pelestarian budaya salah satunya bahasa Bali yang merupakan warisan leluhur bagi masyarakat Bali. Sederhananya dengan menambahkan caption berbahasa bali dalam unggahan instagram.

3. Membuat tampilan konten instagram yang menarik dengan menambahkan video, komik atau lainnya yang dapat mendukung eksistensi bahasa Bali. Tampilan konten yang menarik sehingga dapat menggugah para pengguna instagram khususnya generasi muda agar mau belajar bahasa Bali dan sebagai masyarakat Bali, mampu mempertahankan keberadaan bahasa ibu yaitu bahasa Bali.

\section{Kesimpulan}

Bahasa adalah salah satu kebutuhan utama dan memiliki peran yang sangat penting dalam kehidupan bermasyarakat. Bahasa Bali sebagai bahasa ibu merupakan salah satu identitas dan warisan leluhur yang harus dipertahankan, dipelihara dengan baik keberadaannya. Perkembangan teknologi saat ini seperti halnya media sosial, memberi ruang baru bagi sastrawan, penggiat bahasa Bali dalam berkarya sekaligus membagikan edukasi berupa postingan-postingan yang berkaitan dengan pelestarian bahasa Bali. Salah satunya adalah dengan media social instagram. Melaui program ini, banyak karya-karya berbau bahasa Bali yang luar biasa telah diciptakan, yang secara khusus dapat menarik perhatian generasi muda untuk menggunakan bahasa Bali. Penelitian telah dilakukan pada akun-akun seperti @wikibasabali, @bahasa_bali yang berisikan kamus daring tiga bahasa (Bali-Indonesia-Inggris), perpustakaan virtual, penggunaan anggah ungguhing basa, penggunaan bahasa Bali dalam kehidupan sehari-hari, selain itu pada akun @ beluluk menyajikan hiburan berupa komik berbahasa Bali.

Adapun upaya yang dapat dilakukan dalam menjaga eksistensi bahasa Bali dalam Instagram adalah dengan mengikuti akun-akun yang berkaitan dengan pelestarian budaya salah satunya bahasa Bali, mengunggah konten-konten edukatif yang dapat mendukung eksistensi bahasa Bali bisa dengan menyelipkan humor atau hiburan dengan tampilan konten yang menarik agar dapat menggugah para pengguna instagram khususnya generasi muda agar mau belajar bahasa Bali dan sebagai masyarakat Bali, mampu mempertahankan keberadaan bahasa ibu yaitu bahasa Bali. 


\section{Daftar Pustaka}

Ardiyasa, I. N. (2020). Upaya Penjaminan Mutu Pengajaran Bahasa Bali Dalam Dunia Pendidikan. . PINTU: Jurnal Penjaminan Mutu, 1-2.

Djaharuddin, A. (2017). Dampak Media Jejaring Sosial Terhadap Penggunaan Gaya Bahasa Gaul Pada Siswa Kelas XI SMA Negeri 14 Makassar.

Juwita, E. P. (2014). Peran Media Sosial Terhadap Gaya Hidup Siswa SMA Negeri 5 Bandung: Studi terhadap Pengguna Media Sosial di SMA Negeri 5 Bandung (Doctoral dissertation). Bandung: Universitas Pendidikan Indonesia.

Khaerudin, K. (2008). Menjadikan Bahasa Indonesia yang Bermartabat dan Jati Diri Bangsa. FPBS Universitas Pendidikan Indonesia.

Kridalaksana, H. (2003). Kamus Linguistik. Jakarta: PT Gramedia.

Salsabila, N. (2018). Peran Media Sosial Instagram sebagai Strategi Menjaga Eksistensi Bahasa Indonesia. Retrieved from https://doi.org/10.31227/osf.io/jzksq

Sarwono, J. (2006). Metode Penelitian Kuantiatif dan Kualitatif. Yogyakarta: Graha Ilmu.

Sriasih, S. A. P., Wisudariani, N. M. R., Yasa, I. N. . (2020). Program Kamis Berbahasa Bali Sebagai Upaya Pelestarian Budaya Bali di Sekolah Dasar Mutiara Singaraja . Proceeding Senadimas Undiksha, pp. 14-36.

Suandi, I. N. (2006). Potensi Siaran Berbahasa Bali Melalui Media Elektronik dalam Upaya Pemertahanan Bahasa Bali. Kongres bahasa Bali VI di Denpasar.

Suastra, I. M. (2009). Bahasa Bali Sebagai Simbol Identitas Manusia Bali (Doctoral dissertation). Bali: Udayana University.

Tantra, D. K. (2006). Bahasa, Aksara, dan Sastra Bali dalam Pendidikan. Kongres bahasa Bali VI di Denpasar.

Wirawan, I. M. A., Paryatna, I. B. M. L. (2016). Pengembangan kamus anggahungguhing bahasa bali. Jurnal Nasional Pendidikan Teknik Informatika: JANAPATI, 5(2), 98-107.

Zainal, A. (2016). Memaksimalkan peran media sosial untuk keberhasilan pendidikan dan pembelajaran bahasa Indonesia. 